\title{
Correlation between Fatique and Stress among Female in Caring for the Elderly at Hospitals
}

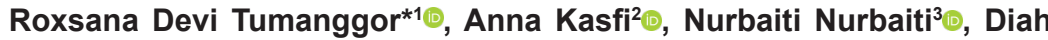 \\ Lestari Nasution ${ }^{4}$ \\ 1, 3, ${ }^{\mathrm{F}}$ aculty of Nursing, Universitas Sumatera Utara, Medan, Indonesia \\ ¿University of Sumatera Utara Hospital, Medan, Indonesia
}

\begin{abstract}
Background: Studies showed that the caregiving process has an impact on physical and psychological health, such as stress and fatigue.

Purpose: This research aims to analyze the correlation between fatigue and stress in female caregivers caring for the hospitalized elderly in Medan, Indonesia.

Methods: This is a correlational study with a cross-sectional approach. Data collection was conducted from March to October 2020 and 42 caregivers participated. The data analysis was performed to analyze for frequency distribution and the Pearson correlation test was used to measure the strength of the correlation between variables.

Results: It was reported that $47.5 \%$ of female caregivers were in the average age range of 47 years, and provided care almost 24 hours per day. The elderly had been sick for less than a year on average and showed some degree of partial dependence. Based on the results of the Pearson correlation test, the value of Sig. $0.000<0.05$ was obtained. Furthermore, the direction of the positive relationship can be seen from the sign of the coefficient (Pearson's correlation of 0.759), which means that the higher the fatigue, the higher the stress level.

Conclusion: These results are expected to be the basic data for future research and should be considered hospitals regarding care for the elderly. This can reduce the impact of the stress on the caregivers' which can affect the quality of care provided.
\end{abstract}

Jurnal Keperawatan

Padjadjaran (JKP)

Volume 9(3), 199-205

(C) The Author(s) 2021

https://doi.org/10.24198/jkp.

v9i3.1669

\section{Article Info}

Received : June 17, 2021

Revised : November 05, 2021

Accepted : November 15, 2021

Published : December 22, 2021

Corresponding author

Roxsana Devi Tumanggor

Faculty of Nursing, Universi-

tas SUmatera Utara, Medan,

Indonesia, Postal address: 20155

Phone: 62 819-1081-9799, E-mail

roxsana.tumanggor@usu.ac.id

\section{Citation}

Tumanggor, R. D., Kasfi, A., Nurbaiti, N., \& Nasution, D. L. (2021) Correlation between Fatique and Stress among Female in Caring for The Elderly at Hospital. Jurnal Keperawatan Padjadjaran, 9(3), 199-205.https://doi.org/10.24198/ jkp.v9i3.1669

\section{Website}

http://jkp.fkep.unpad.ac.id/index php/jkp

This is an Open Access article distributed under the terms of the Creative Commons Attribution-NonCommercial 4.0 International License.

E-ISSN: $2442-7276$

P-ISSN: 2338-5324
Keywords: aged, caregivers, cross-sectional studies, female, mental health.

\section{Introduction}

In 2020 , the elderly growth rate of over 60 years was about $10 \%$ of the total population (Kementrian Kesehatan Republik Indonesia, 2013). In the case of Sumatera Utara Province, it was predicted that the number of elderly people would be $8.3 \%$ by 2020 (Pusat Data dan Informasi Kemenkes RI, 2016), and one out of four elderly would experience illness. Therefore, the role of the family and related parties is necessary for handling illness conditions and the aging process experienced by the elderly (Conley \& St Pierre, 2016).

In general, the elderly are cared for by women in the family such as wives, daughters, daughters-in-law, sisters, and grandchildren (Desbiens et al., 2018). This is linked to the great family structure of Indonesian culture, which is made up of fathers, mothers, children, grandparents, and even cousins, nephews, from both husband and wife. Therefore, these women are responsible for many things at the same time, such as being a mother, wife, caregiver for the elderly as well as a breadwinner with duties and responsibilities that differ from domestic chores (Annisa, 2016).

Research revealed that women with dual roles as family caregivers often experience psychological stress and physical fatigue (Desbiens et al., 2018). This is due to several factors, such as the duration of care, the effects of care, and the decrease in the physical condition of the elderly. This then 
leads to fatigue in the caregivers and tends to lead to psychological symptoms during the caring process (Roth et al., 2015). However, this dual role is often overlooked in healthcare. The stress experienced by the female caregivers showed a high level of emotions, and therefore it has an impact on the poor quality of health provided (Kim \& Schulz, 2008).

In addition, researches related to the burden of the caregivers' have been carried out, both in terms of caring for patients with cancer (Hartnett, Thom, \& Kline, 2016), chronic mental illness (Nuraini et al., 2020), or aging with special medical conditions (Tumanggor, Elfira, \& Aizar, 2020). Therefore, the independent or partial provision of patient care represents a separate burden that has an impact on the physiological and psychological health of the caregivers (Schulz \& Sherwood, 2008). This research has shown that females tend to show a greater psychological burden than males during the caring process (Penning \& Wu, 2016). Furthermore, a qualitative study related to the female caregivers' stress in caring for the elderly at Universitas Sumatera Utara Hospital (Tumanggor, Elfira, \& Aizar, 2020), showed one of the research themes on caregivers fatigue. The research conducted by Johansen et al. (2018) stated that fatigue is one of the impacts in the caring process given to patients that are totally or partially dependent. The higher the dependence level of the patient, the higher the level of caregiver fatigue, which then contributes to the deterioration of the quality of life of the caregivers' (Hong \& Harrington, 2016).

The research conducted by Roth et al. (2015) showed that there was no relationship between fatigue and the stress that caregivers experience during the caring process. This is because of certain conditions such as disabled patient, high dependence levels, financial problems as a result of caring, and the multiple roles of female caregivers in the family (Gérain \& Zech, 2019; Wolff et al., 2016). Other research has also described variables of fatigue and stress in certain populations and conditions. For example, Llanque et al. (2016) showed that fatigue can lead to burnout if the caring process is exposed to long-term stress. Therefore, some of the research above shows the importance of fatigue and stress that female caregivers are exposed to under certain circumstances with long duration.

However, the research on female caregivers' stress has not been extensively conducted in nursing science in Indonesia. Moreover, it also emphasizes the relationship between fatigue and stress experienced by caregivers when caring for the elderly being hospitalized. Although physical and psychological stress during care affects the caregiver in terms of time, finances, physically and mentally, which triggers a decrease in physical health status and fatigue in caregivers (Lynch et al., 2018). If this is related to the caring process for the elderly, then this will worsen the condition and reduce the quality of life of the caregiver's physical and mental health (Wasilewski, 2016).

Moreover, the research conducted by Schrank et al. (2016) showed a significant difference between the burden experienced by female and male caregivers in caring for patients with cancer. This study was carried out with the involvement of 272 caregivers to determine their stress, support, adaptability, expectations, and background. Based on the t-test and chi-square, it was reported that women experienced more burden during the caring process than men. Furthermore, this is related to several factors such as the caregiver's age, emotional adjustment, and the dual roles as caregiver and breadwinner in the family. However, the investigation on the relationship between fatigue and stress among females as family caregivers has not been widely explored in Indonesia. Even though it has various cultures with a certain perspective on women as mothers, wives, and children (Annisa, 2016).

According to Wulansari (2013), gender inequality is often occurred in Asia, such as in Indonesia. Women are struggling with self acknowledgment in society related to the social-economic status, occupation, financial offer, and many issues. In some cultures, women are treated differently in Indonesia. It is very often that women do not have the right to express opinions, and devote themselves only to the family. In fact, as a breadwinner, it is normal when a women's income supports the family financially, including taking care of the elderly. This is one of the factors that contributes to women's mental health. In contrast to western culture, most women there have a legal right to express opinions and regulate life accordingly. Even though Asian and western cultures share most values in the caregiving process, but at least there is no such obligation caring for the elderly in the family, like in Asians. Therefore, it is important to conduct research examining the relationship between female caregiver's fatigue and stress while caring for the elderly with chronic diseases at the Universitas Sumatera Utara Hospital, Medan - Indonesia, to be considered for research related to women's health in the future.

\section{Methods}

This research is a correlational study using the Pearson correlation test approach, which aims to analyze the correlation between fatique and stress among the female caregivers in caring for the elderly at the Universitas Sumatera Utara Hospital (USU Hospital). The population consists of all female caregivers in caring for the elderly at USU Hospital in 2020 , but since there is no record of the family caregiver's population in USU Hospital, therefore the researchers applied the convenience sampling method resulted in a sample of 42 respondents from two inpatient units for adult in USU Hospital from March to October 2020. The female samples were the elderly daughters, wives, grandchildren, sisters, 
Original Article

Correlation between Fatique and Stress

Table 1. Respondent Characteristics

\begin{tabular}{lc}
\hline \multicolumn{1}{c}{ Demographics } & $\mathbf{n ~ ( \% )}$ \\
\hline Age (Years old) & \\
$21-30$ & $5(2.1)$ \\
$31-40$ & $12(5.04)$ \\
$41-50$ & $9(3.78)$ \\
$51-60$ & $7(2.94)$ \\
$61-70$ & $8(3.36)$ \\
$71-80$ & $1(0.42)$
\end{tabular}

\section{Occupation}

Student

Civil Servant

$4(1.68)$

Nurse

$2(0.84)$

Retirement

$3(1.26)$

Unemployment/Housewife

$15(6.3)$

Farmer

$2(0.84)$

Lecturer

$1(0.42)$

Enterpriser

$8(3.36)$

Self Employed

$2(0.84)$

\section{Education Level}

Elementary School

Junior High School

Senior High School

$12(28.6)$

Diploma-3/Bachelor Program

Master Program

Doctoral Program

$1(2.4)$

\section{Marital Status}

$\begin{array}{lc}\text { Single } & 9(21.4) \\ \text { Married } & 30(71.4) \\ \text { Widow } & 3(7.2)\end{array}$

\section{Relationship with the Elderly}

Wife

Child

Grandchild

Younger sister

Niece

Daughter in law

$1(2.4)$

\section{Caregiving Duration}
$<=1$ year
$29(69.0)$
$>1$ year
$13(31.0)$

\begin{tabular}{lc} 
Caregiver Support System & \\
Yes & $26(61.9)$ \\
No & $16(38.1)$ \\
Demographics & Mean \pm SD \\
Age & $46.81 \pm 13.42$ \\
Number of children & $2.31 \pm 2.04$ \\
\hline Total caring time & $21.88 \pm 5.61$ \\
\hline
\end{tabular}


Table 2. Elderly Characteristics

\begin{tabular}{ll}
\hline \multicolumn{1}{c}{ Demographics } & n (\%) \\
\hline \hline Previous Hospitalization History & \\
Never & $19(45.2)$ \\
Ever & $23(54.8)$
\end{tabular}

\section{Fall History}

$\begin{array}{ll}\text { No } & 37(88.1)\end{array}$

Yes

$\begin{array}{ll}\text { Living with the Caregiver } & 30(71.4) \\ \text { Yes } & 12(28.6) \\ \text { No } & \end{array}$

\section{Elderly Barthel Index}

Independent

Partial

Table 3. Pearson Correlation Test Results

\begin{tabular}{lc}
\hline \multicolumn{1}{c}{ Variable } & Stress (p Value) \\
\hline Fatigue & $<0.0001$ \\
\hline$P$ Value $=0.05$ level of significance &
\end{tabular}

nieces or daughters-in-law. And, the hospitalized elderly age was $>60$ years old according to the definition of WHO (World Health Organization, 2001). Some researches related to stress and fatique among family caregivers used variant technique samples to obtain research samples. A research conducted by Cohen et al., (2007) analyze the stress factors among 24 caregivers. This is considered a small sample size, but the samples are collected with time duration, similar to this study.

The data collection was carried out using three instruments namely demographic data, an instrument for measuring fatigue and stress based on the fifth edition of nursing outcome classification in the Indonesian book version. The fatique instrument consist of 19 items and the stress instrument consist of 35 items with yes and no answer choices. The total score ranges from 0-19 for fatique level and 0-35 for stress level. The reliability test from the previous study for fatique was 0.82 (Tiesinga, Dassen, Halfens, \& van den Heuvel, 2001). Before the data collection, each respondent was given an explanation related to the purpose and approval of participation directly. The samples are allowed to be withdrawn during data collection anytime. Furthermore, it passed the ethical test process with letter number: 169/KEP/USU/2020 by the Research Ethics Commission of the Universitas Sumatera Utara, June 30, 2020. The data analysis conducted was univariate, which aims to describe the characteristics of each variable studied. Furthermore, bivariate analysis with Pearson Correlation Test was used to determine the strength of the correlation between fatigue and stress.

\section{Results}

Based on the results, two important elements were obtained, namely data related to the characteristics of the research sample and the Pearson Correlation Test on fatigue and stress variables. Out of the 42 samples, $47.6 \%$ of female caregivers were elderly couples with an average age of 47 years and $52.4 \%$ were working. About $69 \%$ of the caregivers had cared for less than a year. About $62 \%$ of the female caregivers received assistance while caring for the elderly, and $71.4 \%$ were living with the elderly for almost 24 hours of care a day. Furthermore, more than $50 \%$ of the elderly had a partial dependence level on caregivers. This means that the elderly needed assistance in fulfilling their daily needs in several aspects and could be independent in other aspects. Further information on the characteristics of the female caregivers and the elderly are shown in Tables 1 and 2.

The analysis of the Pearson Correlation Test data shows the value of Sig. $0.000<0.05$. This means that there was a significant correlation between fatigue and stress variables. Furthermore, the positive relationship direction is seen from the sign of the coefficient (Pearson Correlation 0.759), which means that the higher the fatigue, the higher the caregiver stress level, as shown in table 2.

\section{Discussion}

Based on the results, it was reported that the majority of female caregivers are wives in the elderly age, with an average age of 47 years. This is a common case because female elderly caregivers 
on average are a couple (Desbiens et al., 2018), and spend more than $50 \%$ of their time providing care. The research conducted by Sharma et al., (2016) stated that female caregivers provide care for about 21 hours per day for sick family members. This is due to several factors, namely obligations as daughters and wives as well as emotional ties. Furthermore, this form of treatment is viewed as a form of family participation, especially in Indonesian families (Annisa, 2016).

These results suggest that $57.1 \%$ of the elderly are partially dependent, therefore caregivers provide many services to meet patients' daily needs, such as eating, drinking, bathing, dressing, and toileting. Fulfilling these four basic needs requires an immediate response, therefore these are considered burdens by the caregiver. Ultimately, full duties and responsibilities, as well as vulnerability to psychological disorders further worsen the health status of female caregivers and can have an indirect impact on the quality of care (Wasilewski, 2016).

Research proves that caregivers with physical and psychological stress during caring tend to be physically and emotionally abusive to the elderly (Lino et al., 2019; Orfila et al., 2018), although some researches show that there was no relationship between high levels of fatigue and stress experienced by women during the caring process. However, certain characteristics in the sample have shown to contribute to the deterioration of the caregiver's health, such as the old age of caregivers, elderly dependency level, and the caregivers' dual role as a partner and breadwinner for the family. This is a predisposing factor in causing fatigue and stress for female caregivers during the caring process (Gérain \& Zech, 2019). And, all of these characteristics revealed in this study result, and contribute to the female caregivers' fatique and stress.

The results indicated that there was a significant correlation between fatique and stress among female caregivers. The more tired the caregiver is in providing care, the higher the stress level they experienced. This is similar with research conducted by Lynch et al., (2018), which reported that female caregivers are prone to fatigue and stress, with several factors contributing to these two variables, such as age and financial problems, which are two important points reported in the results.

According to Herdman \& Kamitsuru (2014), fatigue is one of the terminologies of nursing diagnosis defined by the condition of feeling tired continuously and has a physical and mental impact on an individual daily life. This is a natural human response in dealing with physical stress (Scruggs, 2009). However, if not treated immediately, the quality of care for the elderly will continue to decline, with a deterioration in the quality of life of caregivers (Ho et al., 2009). Therefore, it is important to consider an intervention in the future to reduce fatigue and stress factors experienced by female caregivers, which appear to be the majority group caring for other family members (Desbiens et al.,
2018). This could have a positive impact on the elderly and caregivers in the future.

\section{Study Limitation}

This research was conducted during the COVID-19 pandemic, which reduced the number of hospitalized patients at USU Hospital by $80-90 \%$. Furthermore, due to a lot of misinformation related to the spread of the COVID-19 pandemic in the community, most of the families of patients refused to participate in the research because they believed that their data would be misused. It was very difficult for researchers, although the USU Hospital had made it easier for patients and families by providing information. Therefore, the sample, which consisted of only 42 people, was not a general conclusion that described the conditions of females while being the main caregiver for the elderly at USU Hospital, Medan.

\section{Conclusion}

This research shows a very significant correlation between female caregivers' fatigue and stress experienced during caring for the elderly at USU Hospital. The average respondent that became the sample was elderly couples with an average age of 47 years and provided care almost 24 hours daily. The significant relationship between fatigue and stress is an indication that immediate treatment is needed to overcome caregiver fatigue, and therefore it can reduce the stress impact. Reducing the caregivers' stress level indirectly improves the quality of care for the elderly. This is important in healthcare as family members are an important support system in the caring process. In addition, this research results will contribute to the provision of family caregiver-based nursing interventions. It will develop several specific interventions which might support the hospital services and develop nursing research in the future.

\section{Acknowledgment}

The authors express profound gratitude to the Universitas Sumatera Utara for providing funding for this research. This also applies to female caregivers who were willing to be research samples, perhaps thanking them is not enough because they have been providing valuable data during the data collection process. The authors are also grateful to the USU Hospital for giving permission and facilitating data collection during the research.

\section{References}

Annisa, F. (2016). Burden of family caregiver. Belitung Nursing Journal, 2(1), 10-18. https:// doi.org/10.33546/bnj.7

Cohen, M., Katz, D., \& Baruch, Y. (2007). Stress among the family caregivers of liver transplant recipients. Progress in Transplantation, 17(1), 48-53. https://doi.org/10.7182/ 
prtr.17.1.a651683t34177n77

Conley, D., \& St Pierre, J. (2016). Foundations for gerontological unit I. Jones \& Bartlett Learning, LLC.

Desbiens, N. A., Mueller-rizner, N., \& Virnig, B. (2018). Stress in Caregivers of Hospitalized Oldest-Old Patients. The Journals of Gerontology, 56(4), 231-235. https://doi. org/10.1093/gerona/56.4.M231

Gérain, P., \& Zech, E. (2019). Informal Caregiver burnout? Development of a theoretical framework to understand the impact of caregiving. Frontiers in Psychology, 10(July). https://doi.org/10.3389/fpsyg.2019.01748

Hartnett, J., Thom, B., \& Kline, N. (2016). Caregiver Burden in End Stage Ovarian Cancer. Clinical Journal of Oncology Nursing, 20(2), 1-13. https://doi.org/10.1188/16.CJON.169-173

Herdman, T.H. \& Kamitsuru, S. (2014). NANDA International Nursing Diagnoses: Definitions \& Classification, 2015-2017. Wiley Blackwell

Ho, S. C., Chan, A., Woo, J., Chong, P., \& Sham, A. (2009). Impact of caregiving on health and quality of life: A comparative populationbased study of caregivers for elderly persons and noncaregivers. Journal of Gerontology: Medical Sciences, 64(8), 873-879. https://doi. org/10.1093/gerona/glp034

Hong, M., \& Harrington, D. (2016). The effects of caregiving resources on perceived health among caregivers. Health and Social Work, 41(3), 155-163. https://doi.org/10.1093/hsw/ hlw025

Johansen, S., Cvancarova, M., \& Ruland, C. (2018). The effect of cancer patients' and their family caregivers' physical and emotional symptoms on caregiver burden. Cancer Nursing, 41(2), 91-99. https://doi.org/10.1097/ NCC. 0000000000000493

Kaur Popli, U., \& Panday, R. (2018). Caregivers Burden of Hospitalized Elderly. Journal of Gerontology \& Geriatric Research, 07(05). https://doi.org/10.4172/2167-7182.1000483

Kementrian Kesehatan Republik Indonesia. (2013). Buletin jendela data dan informasi kesehatan. Pusat Data dan Informasi Kemenkes RI.

Kim, Y., \& Schulz, R. (2008). Family caregivers ' strains family caregivers ' strains. Journal of Aging and Health, 20(5), 483-503. https://doi. org/10.1177/0898264308317533

Lino, V. T. S., Rodrigues, N. C. P., de Lima, I. S., Athie, S., \& de Souza, E. R. (2019). Prevalence and factors associated with caregiver abuse of elderly dependents: The hidden face of family violence. Ciencia e Saude Coletiva, 24(1), 87-96. https://doi.org/10.1590/141381232018241.34872016

Llanque, S., Savage, L., Rosenburg, N., \& Caserta, M. (2016). Concept analysis: Alzheimer's caregiver stress. Nursing Forum, 51(1), 21-31. https://doi.org/10.1111/nuf.12090

Lynch, S. H., Shuster, G., \& Lobo, M. L. (2018). The family caregiver experience - examining the positive and negative aspects of compassion satisfaction and compassion fatigue as caregiving outcomes. Aging and Mental Health, 22(11), 1424-1431. https://doi.org/10. 1080/13607863.2017.1364344

Nuraini, T., Tumanggor, R. D., Hungerford, C., Lees, D., \& Cleary, M. (2020). Caregiver burden for people with schizophrenia in Medan, Indonesia. Issues in Mental Health Nursing, O(0), 1-4. https://doi.org/10.1080/01612840.2 020.1847223

Orfila, F., Coma-Solé, M., Cabanas, M., CegriLombardo, F., Moleras-Serra, A., \& PujolRibera, E. (2018). Family caregiver mistreatment of the elderly: Prevalence of risk and associated factors. BMC Public Health, 18(1), 1-14. https://doi.org/10.1186/s12889018-5067-8

Özcan, N. K., Boyacıoğlu, N. E., \& Sertçelik, E. (2017). Reciprocal abuse: Elder neglect and abuse by primary caregivers and caregiver burden and abuse in Turkey. Archives of Psychiatric Nursing, 31(2), 177-182. https:// doi.org/10.1016/j.apnu.2016.09.011

Penning, M. J., \& Wu, Z. (2016). Caregiver stress and mental health: Impact of caregiving relationship and gender. Gerontologist, 56(6). https://doi.org/10.1093/geront/gnv038

Pusat Data dan Informasi Kemenkes RI. (2016, June 03). Situasi lanjut usia di Indonesia. Retrieved January 12, 2021, from https://pusdatin. kemkes.go.id/article/view/16092300002/ infodatin-situasi-lanjut-usia-lansia-diindonesia.html

Roth, D. L., Fredman, L., \& Haley, W. E. (2015). Informal caregiving and its impact on health: A reappraisal from population-based studies. Gerontologist, 55(2), 309-319. https://doi. org/10.1093/geront/gnu177

Schrank, B., Ebert-vogel, A., Amering, M., Masel, E. K., Neubauer, M., Watzke, H., Zehetmayer, S., \& Schur, S. (2016). Gender differences in caregiver burden and its determinants in family members of terminally ill cancer patients. Psycho-oncology, 25(7), 808-814. https://doi. org/10.1002/pon.4005

Schulz, R., \& Sherwood, P. R. (2008). Physical and mental health effects of family caregiving. American Journal of Nursing, 108(9), 23-27. https://doi.org/10.1097/01. NAJ.0000336406.45248.4c

Scruggs, B. (2009). Fatigue: Assessment and management. Home Health Care Management \& Practice, 22(1), 16-25. https:// doi.org/10.1177/1084822309340300

Sharma, N., Chakrabarti, S., \& Grover, S. (2016). Gender differences in caregiving among family - caregivers of people with mental illnesses. World Journal of Psychiatry, 6(1), 7. https://doi. org/10.5498/wjp.v6.i1.7

Tiesinga, L.J., Dassen, T.W.N., Halfens, R.J.G., 
\& van den Heuvel, W. (2001). Sensitivity, specificity, and usefulness of the Dutch Fatigue Scale. Nursing Diagnosis, 12(3), 93106. https://doi.org/10.1111/j.1744-618x.2001. tb00478.x

Tumanggor, R. D., Elfira, E., \& Aizar, E. (2021). Female caregivers stress in caring for hospitalized elderly with chronic disease at Universitas Sumatera Utara hospital: A phenomenology study. Technium Social Sciences Journal, 20(1), 643-651. https://doi. org/10.47577/tssj.v20i1.3511

Wasilewski, M. B. (2016). Caregiver burden - A critical discussion. International Journal of Nursing Studies 50(3), 431-441. https://doi. org/10.1016/j.ijnurstu.2012.10.005

Wolff, J. L., Spillman, B. C., Freedman, V. A., \& Kasper, J. D. (2016). A national profile of family and unpaid caregivers who assist older adults with health care activities. JAMA Internal Medicine, 176(3), 372-379. https://doi. org/10.1001/jamainternmed.2015.7664

World Health Organization. (2001). Men Ageing And Health. Retrieved December 28, 2020, from https://apps.who.int/iris/handle/10665/66941

Wulansari, S. A. (2013). Gender inequality perception: a comparative study of women in Japan and Indonesia. 1-28. https://doi. org/10.1002/9781119990413.ch1 